\title{
Empatía y extrañamiento en el concepto de aura de Walter Benjamin.
}

Empathy and Estrangement

in Walter Benjamin's Concept of Aura.

\begin{abstract}
Ricardo Ibarlucía ${ }^{1}$
Instituto de Filosofía "Ezequiel de Olaso" (CONICET-Centro de Investigaciones Filosóficas) y Universidad Nacional de San Martín
\end{abstract}

\section{Resumen}

El articulo propone una reconsideración de la concepción del aura en Walter Benjamin, a la luz de un recorrido teórico que lleva desde los "Protocolos de ensayos con las drogas" y consideraciones sobre la mímesis hasta "La obra de arte en la época de su reproductibilidad técnica" y sus estudios sobre Charles Baudelaire. La tesis central es que es el concepto de aura de Benjamin implica una dialéctica de empatía y extrañamiento que está profundamente arraigada en la historia de la percepción humana. La caracterización de la experiencia de lo bello de la naturaleza y del arte como aurática consiste, en último análisis, en una derivación de la relación interpersonal que constituye la base del mundo social o, más precisamente, en la transferencia de un proceso perceptivo originario en segunda persona a la actitud que los seres humanos manifiestan frente a entes y hechos experimentados en tercera.

Palabras clave: Percepción, ornamento, velo, lejanía, belleza

\section{Abstract}

The paper proposes a reconsideration of Walter Benjamin's conception of aura, in the light of a theoretical overview that leads from the "Protocols of drug experiments" and his insights on mimesis to "The Work of Art in the Age of Mechanical Reproduction" and his studies on Charles Baudelaire. The main thesis is that Benjamin's concept of aura involves a dialectics of empathy and estrangement which is deeply inscribed in the history of human perception. The characterization of the experience of beauty in nature and art as auratic consists, ultimately, in a derivation of the interpersonal relationship that constitutes the basis of the social world or, more precisely, in the transposition of an original perceptual process in the second person to the attitude that human beings manifest towards entities and events presented from the perspective of the third person.

Keywords: Perception; ornament; veil; distance; beauty 
El concepto de aura ocupa un lugar central de la teoría del arte de Walter Benjamin. Sin embargo, su sentido no es unívoco: de "Pequeña historia de la fotografía" (1931) y "La obra de arte en la época de su reproductibilidad técnica" (1935-1936) a "Sobre algunos motivos en Baudelaire" (1939), la definición del aura evidentemente varía. A esto se añade que, en otros escritos, Benjamin amplía el campo semántico del término más allá de la dimensión estética. En las páginas siguientes, me ocuparé de revisar las distintas formulaciones que el concepto de aura tiene a lo largo de la obra de Benjamin con el fin de mostrar que se funda en una dialéctica de empatía y extrañamiento arraigada profundamente en la historia de la percepción humana. Mi argumento es que la caracterización de la experiencia de lo bello de la naturaleza y del arte como aurática consiste, en último análisis, en una transferencia de la relación interpersonal que constituye la base del mundo social o, más precisamente, en la derivación de un proceso perceptivo originario en segunda persona sobre la actitud que los seres humanos asumen frente a entes y hechos que se presentan bajo la perspectiva de la tercera. ${ }^{1}$

\section{El fenómeno del ornamento}

Empezaré por referirme a una de las más tempranas reflexiones de Benjamin sobre el aura. ${ }^{2}$ En los llamados "Protocolos de ensayos con las drogas" (1927-1934), conjunto de testimonios que recogen sus indagaciones en los efectos del hachís, el opio, la mezcalina y la educalina sobre el aparato perceptivo, Benjamin establece una íntima relación en el plano óptico entre el aura y el ornamento. Así, en el informe de la sesión de marzo de 1930, transcribe las declaraciones que, en pleno trance narcótico, él mismo efectuó sobre la "esencia del aura", en oposición al sentido de esta noción en el campo de la teosofía. La definición ofrecida parece dirigirse específicamente con-

1 Sobre el concepto de aura en el marco de la teoría del arte de Benjamin, cf. Ibarlucía 2020, especialmente 163-198. Agradezco a mis colegas Diana I. Pérez y Eleonora Orlando del Instituto de Filosofía de la Sociedad Argentina de Análisis Filosófico/CONICET sus observaciones $y$ comentarios.

2 Como antecedentes de la reconstrucción histórico-conceptual que aquí ensayamos, remitimos a Fürnkas 2000 y Bratu Hansen 2008. 
tra Rudolf Steiner, para quien el "aura humana" era una irradiación de la interioridad, multicolor y envolvente, semejante a "una nube (con forma ovoidal)" (1922 146). Para Benjamin, en cambio, se trata de un fenómeno de la percepción, que comporta tres aspectos:

En primer lugar, el aura auténtica aparece en todas las cosas, no solo en determinadas, como la gente imagina. En segundo término, el aura cambia a fondo y fundamentalmente con cada movimiento de la cosa que es su aura. En tercer lugar, el aura auténtica de ninguna manera puede ser considerada como el inmaculado y mágico rayo espiritualista representado y descrito en los libros místicos de divulgación. Por el contrario, la característica distintiva del aura auténtica es el ornamento, un contorno ornamental [ornamentale Umzirkung] en el cual el objeto o ente se mantiene apretado como dentro de un estuche. Nada expresa tan precisamente quizás el concepto de aura auténtica como las últimas pinturas de Van Gogh, donde el aura -así podrían describirse estos cuadros- ha sido pintada en todas las cosas. (GS VI 590) ${ }^{3}$

Esta inicial representación del aura como ornamento tiene un correlato en las "Notas sobre el crock" (1932). En este protocolo, Benjamin afirma que por medio del crock - nombre que junto con Selz daban al opio- es posible alcanzar la repentina conciencia de "penetrar en ese universo oculto, generalmente inaccesible, de superficies que constituyen el ornamento" (GS VI 603). Esta experiencia, común en la infancia y en estados febriles, tendría dos rasgos fundamentales: la polivalencia y su carácter recurrente. En la alucinación del crock, la "significación" o "interpretabilidad múltiple que tiene en el ornamento su fenómeno originario" se manifiesta bajo la circunstancia de que los objetos individuales -por ejemplo, "un decorado o la pintura de un paisaje"- se dejan ver "desde lados distintos [...], como un tejido o una configuración de líneas" que se transforman y reagrupan creando continuamente nuevas formas (Ibid. 604). Las cosas más banales del entorno - como los utensilios del propio fumador de opio- aparecen "dispuestas en series", "en sucesiones interminables", "con formas ani- 
males o vegetales", como "bosquejos apenas modelados de un ornamento primitivo" (Id.).

En la fantasía del crock, los objetos que componen el mobiliario cotidiano adquieren una sorprendente fisonomía: "Las cortinas son intérpretes del lenguaje del viento. Dan a cada soplo la forma y la sensualidad de las formas femeninas. Y a[l] fumador que se sumerge en sus juegos le permiten disfrutar de todos los placeres q[ue] una bailarina consumada pueda prodigar" (Id.). Las filigranas del cortinado, sin embargo, no solo se convierten en instrumento de juego; el fumador las toma como "patrones", "moldes" o "plantillas" [Schablone], que "aplica al paisaje para transformarlo del modo más peculiar", subordinando "el paisaje que aparece detrás, más o menos como el arreglo de ciertos sombreros subordina las plumas de pájaros o la altura de las flores" (Id.). Para ilustrar "cómo las cortinas de encaje gobiernan la visión del paisaje", Benjamin proporciona el ejemplo de algunas tarjetas postales en las que la frase Saludos desde Bad Ems "divide la ciudad en imágenes del paseo del balneario, la estación de ferrocarril, el monumento al emperador Guillermo, la escuela y los altos de Carolina, cada una delimitada en su pequeño marco" (Id.).

\section{2 - La mirada de las estrellas}

Un posterior tratamiento del concepto se encuentra entre los borradores del ensayo de Benjamin sobre la mímesis, cuya primera versión se titula "Doctrina de la semejanza" y la segunda "Sobre la facultad mimética" (1933). La observación destaca a la vez la génesis antropológica del aura y la inscripción de la mímesis en la historia de la percepción humana. En los pueblos primitivos, apunta Benjamin, puede vislumbrarse una relación entre la experiencia la astrología y el aura: "Hay seres terrenales y cosas que desde las estrellas devuelven la mirada a quienes han levantado primero sus ojos al cielo. ¿Son los astros, con su mirada desde la lejanía, el fenómeno originario [Urphänomen] del aura?" (GS II/3 958). En efecto, la contemplación habría sido el primer organon de la mímesis y "el ornamento que retiene la mirada de las estrellas", su modelo más antiguo y "el prescolar de la empatía" (Einfühlung) (Id.).

La declinación de la facultad mimética y la desintegración del aura, 
consiguiente, serían las dos caras de una "crisis de la percepción" -como escribe Benjamin en "Sobre algunos motivos en Baudelaire" (GS I/2 645)que en el campo de la ciencia se anuncia en el florecimiento de la astronomía moderna con Copérnico, Tycho Brahe y Kepler, mientras que en el del arte lo hace con el Barroco. Esta crisis, susceptible de ser reconocida en todas "las épocas inclinadas a la expresión alegórica", conlleva la sustitución del misterio por el enigma, afirma Benjamin en el convoluto "J" del Libro de los pasajes:

La alegoría conoce muchos enigmas, pero no tiene misterio. El enigma es un fragmento que, encajado con otro fragmento, forma un todo. El misterio ha sido sugerido en todas las épocas por la imagen del velo, que es un viejo cómplice de la lejanía. La lejanía aparece velada. Al contrario que de la pintura del Renacimiento, por ejemplo, el Barroco no está siquiera ligado en parte a ese velo. Más bien lo desgarra ostensiblemente y aproxima incluso, como lo muestran particularmente sus pinturas sobre los techos, la lejanía celeste para crear una proximidad que debe sorprender y desconcertar. (GS V/2 461462)

En la sociedad surgida de la Revolución Industrial, esta crisis del aura se evidencia no solo en la fotografía, el cine y otras manifestaciones del arte de masas, sino también en el vasto dominio de la experiencia humana, a través del desvanecimiento de las estrellas en un cielo que en las grandes metrópolis "se cierra como una alcoba", como dice Charles en uno de los versos del poema "El crepúsculo de la tarde" de Las flores del mal (1857-1862):

La gran ciudad no conoce el verdadero crepúsculo. Al menos, la iluminación artificial la priva de su transición hacia la noche. La misma circunstancia hace que las estrellas se disipen en el cielo; su aparición, sobre todo, pasa inadvertida. Los términos en los cuales Kant definía lo sublime, "la ley moral en mí y el cielo estrellado sobre mi cabeza", no habrían podido ser concebidos por un habitante de las grandes ciudades. (GS V/1 433; KpV 162; Baudelaire 1991 138) 
Otra anotación en el convoluto " $Q$ " del Libro de los pasajes relaciona la crisis del aura en las grandes ciudades con "el hecho de que los cambios de iluminación que el día aporta a un paisaje se desarrollen en un cuarto de hora o media hora en los dioramas" (GS V/II: 657). En las vistas que ofrecen estos espectáculos ilusionistas concebidos hacia 1822 por Louis Daguerre, pionero de la fotografía, en los cuales se simulaba el movimiento del sol y la caída del crepúsculo, Benjamin identifica un fenómeno óptico particular:

una especie de anticipación juguetona del cine, una aceleración espiritual, un poco maliciosa, del desarrollo del tiempo, una aceleración "danzante" que hace pensar, per contrarium, en la desolación de una $\mu$ í en Nadja [1928], en uno de cuyos capítulos se habla de un pintor que "al atardecer ha colocado su caballete frente al puerto viejo de Marsella y que, a medida que la luz declina, cambia sin cesar la iluminación del cuadro, hasta que éste no muestra más que la oscuridad. (Id.; cf. Breton 1964175 n.1)

La producción en masa -sostiene Benjamin en el convoluto "J" del Libro de los pasajes- fue "la principal causa económica de la desintegración del aura y la lucha de clases su principal causa social" (GS V/1 433). La aceleración del ritmo de la producción mecanizada -precisa en el convoluto " $K$ " -anunció "una enorme intensificación del ritmo de la vida", cuyos primeros síntomas fueron analizados por Karl Marx (GS V/1 497). En "La obra de arte en la época de su reproductibilidad técnica", focaliza en "la forma y el modo en que se organiza la percepción" en la era del capitalismo industrial (GS I/2 439, 478,712, VII/2 354; KGA XVI 57-58, 101, 168, 214). Los seres humanos se relacionan cada vez más con el mundo -con las demás personas y con los objetos que los rodean- en un medium tecnificado que exonera a los órganos del cuerpo y modifica las condiciones de la percepción sensorial: "El aspecto de la realidad libre de aparatos resulta sobremanera artificial y la visión de la realidad inmediata se convierte en la flor azul en el país de la técnica (GS I/1, 495, VII/2, p. 373; KGA XVI, 127, 234). 


\section{3· Nimbo y melancolía}

"¿Qué es propiamente el aura? Una singular trama de espacio y tiempo: la aparición única de una lejanía, por cercana que pueda estar", escribe Benjamin en "La obra de arte en la época de su reproductibilidad técnica", retomando textualmente la definición ofrecida en "Pequeña historia de la fotografía" (GS I/1 440, 479, 712, VII/1, 355, II/1 378-379; KGA XVI 58, 102, $168,215)$. Con esta definición, podemos decir que ya nos encontramos cabalmente frente lo que Benjamin, en una carta a Karl Thieme de diciembre de 1937, considera como "la fundación rica en consecuencias del concepto de aura" (GB V 632). Si bien aquí, como en el ensayo de 1931, el concepto se introduce para el análisis de objetos históricos, no se limita en absoluto a ellos y la mejor manera de ilustrar su significado, según explica el propio Benjamin, es a través del ejemplo de una experiencia aurática de un "objeto natural":

\section{Seguir con la mirada, mientras descansamos en una tarde de verano, una cadena de montañas en el horizonte o una rama que arroja su sombra sobre el que reposa: eso es respirar el aura de aquellas montañas, de aquella rama. (GS I/2 440, 479, 713-714, VII/1 353; KGA XVI 58, 102, 169, 215)}

No sin razón, se ha dicho que el ejemplo parece inspirarse en las consideraciones de Ludwig Klages sobre el "nimbo" o "aura" (cf. Moretti 2013 149-159).4 En las páginas de Der Geist als Widersacher der Seele [El espíritu como adversario del alma], el aura se asimila a lo que los antiguos llamaban el "genius loci", la peculiar "atmósfera" de un ser humano, una casa, un vecindario, siempre única y distinta (Klages 1929 1103). En mayor o menor medida, todas las obras de arte la poseen. Así, por ejemplo, en comparación con los poetas clásicos, "los románticos parecen estar envueltos por una intensa atmósfera", pero el aura de cada uno de ellos jamás es la misma: la de Friedrich Hölderlin es "algo que podríamos denominar un éter transparente"; la de Joseph Görres, "un vapor que se adensa nebuloso"; la 
de Joseph von Eichendorff, "un azul remoto y oro" (Ibid. 918). Sin embargo, el aura nada tiene que ver con la evolución de los estilos y menos aún con el "significado espiritual" de las obras, como lo prueba el hecho de ningún romántico ha alcanzado jamás el nivel de Goethe o Schiller: "Con el aura, y exclusivamente con ella (y en forma proporcional a su fuerza), lo que se manifiesta es el empuje hacia afuera de la esencia terrenal que solo los tiempos de un retorno telúrico unifican" (Ibid. 844).

Si nos atenemos a estas formulaciones, el aura parecería ser una propiedad intrínseca a las cosas. Sin embargo, Klages explica que el "alma" y la "imagen" son los "polos focales" de una misma experiencia (Id.). El nimbo o aura es el "halo" reluciente con el que "la mirada erótica envuelve las imágenes del mundo" y las transfigura: las "imágenes intuitivas" de las cosas devienen "imágenes originarias" [Urbilder], "apariciones de la lejanía": lo cual echa luz sobre la noción benjaminiana de "imagen de dialéctica" [dialektisches Bild] que articula internamente el Libro de los pasajes (Ibid. 1207; GS V/1 595)..$^{5}$ Un hecho que acaba de suceder y todavía está presente en el alma del contemplador es extrañado, alejado, proyectado hacia un tiempo remoto y teñido de anhelo, como la profundidad azul del horizonte. Así, en virtud de este "velo luminoso", la imagen se despliega con su propio universo, como en los retratos, cuyos contornos "borrosos, difusos, inasibles" permiten que, "a pesar de la perceptibilidad del núcleo", llegue a manifestarse su interior, lo que los románticos llamaban el "infinito" (Ibid., 845). El aura no es la pura fenomenalidad de la visión, sino la imagen en su realidad efectiva; "ella es a la vez plena manifestación y pleno acontecer", agrega Klages (Id.): la mirada que el sujeto dirige al objeto y la que el objeto le devuelve se determinan recíprocamente:

Que la fuerza de la contemplación decaiga porque el aura se extingue, o que el aura se extinga porque la fuerza de la contemplación decae, es algo que puede variar de un caso a otro y tiene poca importancia, si sabemos que, gracias a la polaridad de los procesos, no puede haber ninguna modificación de lo uno sin que lo otro se modifique. (Ibid. 1212) 
Tan sugestiva como la posible influencia de Klages es la hipótesis según la cual la concepción del aura de Benjamin se haya modelado a partir de la noción de ambiance (ambiente, atmósfera) de Léon Daudet (cf. Agamben 1977 53). Más relevantes, con todo, resultan las definiciones del concepto de aura que el propio Daudet ofrece en diversos textos de Daudet que Benjamin leyó atentamente, algunos de ellos citados en el Libro de los pasajes. En su ensayo Mélancholia [Melancolía], por ejemplo, considera el aura como "una exacerbación de la ambiance", que aparece en ciertos delirios y alteraciones que aumentan e intensifican la melancolía y que contados escritores han sabido evocar como Baudelaire, "el poeta, precisamente, del aura" (Daudet 1928a 110-111). Paralelamente, en Les pèlerins de Emmaüs [Los peregrinos de Emaús], sostiene que se trata de una "perturbación profunda" que se sitúa "más allá del malestar y de la angustia": "Aura significa soplo. Es el escalofrío sentido en el momento de las graves intoxicaciones y que experimentan los grandes nerviosos en los prolegómenos de sus crisis (Daudet 1928b 99; cf. GS VI 341). ${ }^{6}$

Pero es, sobre todo, la caracterización que Daudet brinda en su ensayo "Baudelaire, la malaise et l'aura" [Baudelaire, el malestar y el aura], recopilado en Flambeaux [Antorchas], la que me interesa particularmente recordar. Retomando textualmente la definición precedente, Daudet opone en este texto el concepto de aura al de "euforia", como un estado de "malestar exasperado y continuo, con una sensibilidad paroxística", y se pregunta si el autor de Las flores del mal no ha buscado, "por afectación y transferencia psíquica", renovar la aventura del príncipe Hamlet:

La vida interior [...] de Charles Baudelaire [...] parece haber [...] transcurrido entre las alternativas de la euforia y del aura. De ahí el doble carácter de sus poemas que, unos, representan una beatitud luminosa y, otros, un estado de negros remordimientos, de melancolía sensual, de vago anhelo, de taedium vitae. (Daudet 1929205-206, 212; cf. GS V/1 318-340)

6 La formulación podría derivar de Jean-Martin Charcot, maestro de Daudet en el Hospital de La Salpêtrière, que se había ocupado del aura en sus lecciones y extendió la aplicación científica del término a la descripción de "los signos y los síntomas" constitutivos de los "fenómenos premonitorios" de los accesos de histeria (Carnevali 2006 131; cf. Charcot 1892-93 I 451). 


\section{$4 \cdot$ El sueño del mundo}

En "La obra de arte en la época de reproductibilidad técnica", el ejemplo del paisaje al que nos referimos anteriormente sirve para ilustrar la definición del aura, "en categorías de percepción espacio-temporal", como "la aparición irrepetible de una lejanía", no obstante la proximidad material que exista entre el sujeto y aquello que contempla (GS I/2 480 n.7). De ello pueden extraerse dos corolarios: por un lado, no cabe establecer ninguna distinción ontológica entre el aura de un objeto natural y un objeto histórico; ${ }^{7}$ por otro, el aura en cuanto tal no es una propiedad interna del objeto, sino en todo caso una propiedad relacional, que designa un modo específico de recepción: la singular manera de darse del objeto como una imagen que se retrae en un halo de ensueño y arrastra al sujeto en una distancia siempre inalcanzable

En sentido estricto, la pérdida del aura no hace referencia sino a la declinación de este régimen perceptivo. Entre las invenciones del mundo industrial, sostiene Benjamin en el convoluto "J" del Libro de los pasajes, "la reproducción masiva de la imagen" ha jugado un papel decisivo en este proceso (GS V/1, 425). Más específicamente, en "Sobre algunos motivos en Baudelaire", la desintegración del aura se asocia con el nacimiento de la fotografía: "Lo que en la daguerrotipia debía sentirse como inhumano, y se diría como mortal, era que la mirada tenía que dirigirse al aparato (por lo demás durante bastante tiempo), mientras el aparato tomaba la imagen del hombre sin devolverle esa mirada" (GS I/2 646). En la mirada humana, en cambio, está siempre implícita "la espera de ser correspondida": la experiencia del aura descansa, por el contrario, en la posibilidad de sentir, aunque más no sea por un momento, que aquello que miramos -otra persona, un animal o cualquier cosa inanimada- alza la vista y nos devuelve la mirada (Id.).

En sus rasgos esenciales, el aura denotaría un modo de "perceptibilidad" que Novalis identificaba con la "contemplación atenta" (Id.; cf. Novalis 1978 II 147). ${ }^{8}$ Su experiencia descansa en la extensión de un com- 
portamiento social característico a las relaciones entre el ser humano y los objetos de su mundo circundante: "Quien es mirado o cree serlo levanta los ojos. Percibir el aura de una cosa significa conferirle la capacidad de mirar" (GS I/2 646-647). La misma tesis sobre la experiencia originaria del aura reaparece en uno de los fragmentos de "Parque central" (1939-1940): "Deducir el aura como transferencia sobre la naturaleza de una experiencia social entre los seres humanos: la mirada es correspondida" (GS I/2 670). La falta de esta correspondencia, por el contrario, es síntoma de su desaparición. Así, en uno de los manuscritos descubiertos en la Biblioteca Nacional de France en 1992 -tres hojas arrancadas de un bloc publicitario de Acqua S. Pellegrino, que datan de la estadía de Benjamin en San Remo en 1937- la erradicación de esta mirada es explicada históricamente a luz de la exacerbación de la lucha de clases:

¿Qué es el aura?

La experiencia del aura reposa sobre la transferencia de una manera habitual de reaccionar en la sociedad humana sobre la relación de la naturaleza con el hombre. Quien es o cree ser mirado levanta su mirada, responde con una mirada. Hacer la experiencia del aura de un fenómeno o de un ente es darse cuenta de su capacidad de levantar los ojos o de corresponder con una mirada. Esta capacidad está llena de poesía. Donde un hombre, un animal o un ser inanimado, bajo nuestra mirada, levanta la propia mirada, nos transporta en la lejanía. Su mirada sueña y nos arrastra en su sueño. El aura es la aparición de una lejanía, por cercana que pueda estar. Las palabras mismas tienen su aura. [Karl] Kraus la describió muy precisamente: "Cuanto más de cerca se mira una palabra, tanto más lejos la palabra mira."

Mientras haya aura en el sueño, habrá aura en el mundo. Pero el ojo despierto no olvida la fuerza de la mirada cuando el sueño se ha extinguido completamente en él. Al contrario, solo entonces su mirada se torna verdaderamente fuerte. Deja de parecerse a la mirada de la amada que levanta los ojos bajo la 
mirada de su amante. Empieza a asemejarse a la mirada con la cual el despreciado responde al que lo desprecia y con la cual el oprimido responde a la mirada del opresor. En esta mirada, la lejanía ha sido totalmente erradicada. Es la mirada de quien ha despertado de todos los sueños, de los nocturnos como de los diurnos.

La capacidad para lanzar este tipo de mirada puede emerger por etapas. Lo hace cuando la tensión entre las clases ha superado cierto grado. Es de interés para los que pertenecen a una de estas dos clases, la de los opresores o de los oprimidos, mirar a la otra clase. Pero ser el objeto de esa mirada es experimentado por los otros como penoso y perjudicial. Así se forma ese estado en el que nos preparamos para evitar la mirada del enemigo de clase. Esta movilización es sobre todo amenazante entre los que constituyen la mayoría. De lo cual resulta una antinomia. Las condiciones en las cuales vive la mayoría de los explotados se distancian cada vez más de las de la minoría que manda. Cuanto más crece el interés de estos últimos en controlar a los primeros, tanto más precaria se vuelve la satisfacción de ese interés.

Quienes sacan provecho del trabajo del proletariado no se exponen en absoluto a la mirada de los obreros. Las miradas que los esperan allí amenazan con ser cada vez más feroces $y$, en tales condiciones, la posibilidad de estudiar tranquilamente a los miembros de las clases inferiores, sin ser objeto a la vez de un estudio de su parte, es de la más alta importancia. Una técnica que hace esto posible es inmensamente tranquilizadora, aun si es empleada con otros fines. Puede disimular durante largo tiempo cómo la vida en la sociedad humana se ha vuelto peligrosa. Sin el cine, la desintegración del aura se experimentaría en un grado que ya no sería soportable. (WBA 264 2; KGA XVI 304-306) 


\section{$5 \cdot$ Promesa de felicidad}

En este manuscrito, Benjamin define el aura, en su más amplia y profunda dimensión antropológica, como la transferencia de la perspectiva de segunda persona sobre la que se fundan las relaciones interpersonales al comportamiento que los seres humanos asumen frente a objetos que se ofrecen bajo la perspectiva de la tercera. La mirada soñadora se diferencia aquí no sólo de la mirada objetivante del conocimiento técnico-científico, sino también y fundamentalmente de la mirada deshumanizada y ferozmente cargada de desprecio del opresor y su reverso: la mirada de rencor con la que el explotado responde a su enemigo de clase. ${ }^{9}$ La mirada soñadora, por el contrario, es "un punto fontanal de la poesía", escribe Benjamin en una nota a pie de página de "Sobre algunos motivos en Baudelaire", que retoma, casi palabra por palabra, el primer párrafo de este texto (GS I/2 647). En las sociedades capitalistas, afirma otro de los manuscritos de la Biblioteca Nacional de Francia, solo el cine parece ser capaz de retener aún esa belleza de la que Stendhal -citado por Nietzsche y Baudelaire- decía en su ensayo Del amor (1822) que era "la promesa de felicidad" propia de cada pueblo y cada época:

¿Conoces Los Peregrinos de Emaús de Rembrandt? ¿Al menos por la reproducción? -Sí. Le di una mirada al cuadro, el domingo en que recorrí el Louvre a las apuradas; pero lo conozco mejor por la reproducción. Jules Romain. Crime de Quinette, p. 174.

La belleza del cine es una belleza no aurática. Esta belleza no aurática se distingue de la belleza aurática en que va acompañada de una nitidez llevada al extremo. Su belleza está en relación con la ciencia. La belleza matemática podría ser su modelo. La función propia del cine es presentar las cosas despojadas del aura en descomposición. El cine, entre otras cosas, restituye lo natural amenazado en lo más profundo por la pérdida del aura, nos restituye el paisaje. Si la belleza es la promesa de felicidad, el cine es la única promesa que nos fue 


\section{dada en tiempos de una despiadada lucha de clases. (WBA, 264 1; KGA XVI 307) ${ }^{10}$}

Este párrafo resulta decisivo para terminar de comprender el alcance de la teoría del aura de Benjamin. La crisis de la percepción, que en "Sobre algunos motivos en Baudelaire" se encuentra en la base de la pérdida del aura, es consecuencia de los profundos cambios que el capitalismo ha introducido en la organización social y las condiciones materiales de existencia, afectando de manera decisiva las relaciones interpersonales. En los ojos de los habitantes de las grandes ciudades, la mirada soñadora en la lontananza ha cedido su lugar a "la mirada atenta a la seguridad" (GS I/2 650). Cuanto más se ha dado cuenta Baudelaire de este hecho, tanto más claramente ha plasmado la decadencia del aura en su poesía. Así, en casi todos los poemas de Las flores del mal (1857-1861) en los que habla de la mirada humana, Baudelaire "describe ojos de los que se podría decir que han perdido la capacidad de mirar", ojos que solo reflejan la ausencia del otro, ojos que "ya no conocen la lejanía" y que adquieren en todo caso el atractivo que les ha conferido "la economía de sus instintos" (Ibid. 648-649).

Ahora bien, en la misma medida en que el aura desaparece de la mirada de los habitantes de las grandes urbes, también la experiencia de la belleza se torna problemática, ya que su posibilidad deriva de esa mirada. En efecto, la destrucción de la bella apariencia y la pérdida del aura son "fenómenos idénticos", leemos en un fragmento de "Parque central" (GS I/2 670). La afirmación clarifica lo que Benjamin señala en "La obra de arte en la época de su reproductibilidad técnica": "El significado de la bella apariencia se funda en la época de la percepción aurática toca a su fin" (GS VII/2 3368 n. 10; KGA XVI 119). En otras palabras, el "fundamento experiencial" de la belleza es el aura: la bella apariencia, como realidad aurática", todavía se respira en el personaje de Ottilie en Las afinidades electivas de Goethe: "Lo bello no es ni el velo ni el objeto velado, sino el objeto en su velo" (Id.; GS I/2 195). Tal es la visión del arte de la estética clásico-romántica alemana: lo bello aparece "a través de su velo, que no es otra cosa que el aura" (GS VII/2

10 En original, la cita entrecomillada de Jules Romain se encuentra en francés. Para la definición de la belleza, cf. Stendhal 1927 I 8o, Nietzsche KSA V 349, Baudelaire 1992346. 
3368 n. 10; KGA XVI 119-120).

Un par de fragmentos de juventud, fechados hacia 1920, permiten rastrear el origen de esta concepción de lo bello. En el primero, Benjamin sostiene que la idea de lo bello es "la plasmación visible del misterio" y su idea, "la naturaleza bella (del cuerpo)": "El arte busca satisfacer la idea de la belleza y alcanzar su ideal. La belleza como cuerpo se asienta en el ideal, en el arte como participación en ella. El arte solo participa de la belleza" (GS VI 128-129). El segundo texto dice: "Todo lo que es bello está dotado de apariencia. Todo lo elaborado artísticamente es bello, porque de alguna manera está dotado de vida" (Ibid. 129). Benjamin parece retomar estas consideraciones en "Sobre algunos motivos en Baudelaire", cuando asevera que el arte aspira a la belleza de la naturaleza y, al imitarla, la "restituye", la "hace venir (como Fausto a Helena) de las profundidades del tiempo" (GS I/2 646). El aura de la obra de arte, el velo a través del cual se manifiesta su belleza, es literalmente un peculiar entramado de espacio y tiempo:

Lo bello en su ser histórico responde a un llamado a reunirse con quienes lo han admirado antes. El sobrecogimiento de la belleza es un ad plures ire, como los romanos llamaban a la muerte. La apariencia en la belleza consiste, en este sentido, en que el objeto idéntico alrededor del cual la admiración se suscita no está en la obra. Esta recolecta aquello que las generaciones anteriores han admirado en él. (Ibid. 638-639 n.)

\section{6 - La obra del tiempo}

A manera de conclusión, quisiera referirme al último escrito publicado por Benjamin. En una carta a Max Horkheimer, fechada en marzo de 1940, Benjamin dice haber descubierto en Le Regard [La mirada] (1939), una reciente obra de Georges Salles, curador entonces del Departamento de Artes Orientales del Museo del Louvre, sorprendentes afinidades con sus ideas estéticas, entre ellas una "descripción del aura" que sería totalmente concordante con la que él mismo ha desarrollado en "Sobre algunos motivos en Baudelaire": ": un modo de percepción por el cual investimos a los objetos, a las cosas inanimadas, de la capacidad de alzar la vista y devolvernos la 
mirada (GB IV 418).

En la reseña de la obra, aparecida dos meses más tarde en la Gazette des Amis des Livres bajo la forma de una carta a Adrienne Monnier, editora de la publicación, Benjamin argumenta que Salles, entre otras virtudes, se muestra receptivo "al encanto que puede otorgar a las obras la acción del tiempo" (GS III 593; KGA XIII/1 527). Esta acción se desarrollaría tanto en un plano espiritual como material: las obras maestras se verían no solo enriquecidas por las miradas que les han dirigido las sucesivas generaciones, sino también concluidas en su materialidad. Salles mismo, dice Benjamin, confiesa haber a menudo "preferido a la singularidad de un objeto nuevo la pieza anticuada, que el envejecimiento ha apisonado en su forma esencial" (GS III 593; KGA XIII/1 528; Salles 1992 21).

Es esta mirada sobre las cosas, mezcla de identificación empática y extrañamiento, la que coincide con su propia concepción del aura: "el modo de ver de un ojo soñador, de un ojo sumergido en los años profundos desde donde nos saludan (como la claridad de un astro desde hace mucho extinguido) esos 'seres desaparecidos a las miradas familiares' que son las obras" de arte", escribe Benjamin entrecomillando las palabras finales del soneto "Obsesión" de Las flores del mal (Id.; Baudelaire 1991 118). Consciente de que la belleza "viene de lejos y se prolonga", Salles ha trabajado calladamente movido por el deseo de saber "bajo qué aspecto renacerá en la perspectiva de los siglos todo lo que la marca con el signo del presente" (GS III 594; KGA XIII/1 528; Salles 1992 120). Según Benjamin, bien podría haber hecho suyos estos versos de Victor Hugo: "No, el tiempo no quita nada a las cosas. / Más de un pórtico por error alabado, / En sus lentas metamorfosis/ Llega por fin a la belleza" (OEC XVII 385). Quizás lo mismo podría haber dicho de sí.

\section{7 - Bibliografía}

Agamben, Giorgio. "Baudelaire o la merce assoluta". Stanze. Le parola e il fantasma nella cultura occidentale, Turín: Einaudi, 1977, 49-54.

Baudelaire, Charles. Les Fleurs du Mal, ed. Jean Dupont, París: Flammarion, 1991.

Baudelaire, Charles. Critique d'art suivi de Critique musicale, ed. Claude Pi- 
chois, pres. Claire Brunet, París: Gallimard, 1992.

Benjamin, Walter. Gesammelte Schriften (GS), ed. Rolf Tiedemann y Hermann Schweppenhäuser, con la colab. de Theodor W. Adorno y Gershom Scholem, 7 ts., 14 vols. y 3 supl. Fráncfort del Meno: Suhrkamp, 1972-1999.

Benjamin, Walter. Gesammelte Briefe (GB), ed. Christoph Gödde y Henri Lonitz (Theodor W. Adorno Archiv), 6 ts., Fráncfort del Meno: Suhrkamp, 1997-2000.

Benjamin, Walter. Werke und NachlaB. Kritische Gesamtausgabe (KGA), ed. Christoph Gödde y Henri Lonitz con la colab. del Walter Benjamin Archiv, 21 ts., Berlín: Suhrkamp, 2008 ss.

Benjamin, Walter. "Was ist Aura?", Berlín: Akademie der Künste, Walter Benjamin Archiv (WAB), 264, 1937.

Benjamin, Walter. "Zür Aura und zür Reproduktionsarbeit in allgemeinen", Berlín: Akademie der Künste, Walter Benjamin Archiv (WAB), 264, 1936-1937.

Block, Richard. "Walter Benjamin und Ludwig Klages", Arcadia 35 (2000): 117-136.

Bratu Hansen, Miriam. "Benjamin's Aura”, Critical Inquiry 34/ 2 (2008): 336375.

Breton, André, Nadja. ed. revisada por el autor, París: Gallimard, 1964.

Carnevali, Barbara. “'Aura' e 'ambiance': Léon Daudet tra Proust e Benjamin", Rivista di Estetica, 33/3 (2006): 117-141.

Charcot, Jean-Martin. Clinique des maladies du système nerveux. Leçons $d u$ Professeur, Mémoires, Notes et Observations parus pendant les années 1889-9o et 1890-91 et publiés sous la direction de Georges Guinon, 2 ts., París: Aux Bureaux du Progrès Médical, 1892-1893.

Daudet, Léon. Mélancholia : Courrier des Pays-Bas, 3 París : Bernard Grasset, 1928 .

Daudet, Léon. Les pèlerins d'Emmaüs: Courrier des Pays-Bas, 4, París: Bernard Grasset, 1928b.

Daudet, Léon. Flambeaux: Rabelais, Montaigne, Victor Hugo, Baudelaire, París: Bernard Grasset, 1929.

Desideri, Fabrizio. "Tendere l'arco dell'immagine. Dialektisches Bild e Fiat iustitia". Alla fine delle cose. Contributi a una storia critica delle immagi- 
ni, ed. Daniele Guastini, Alessandra Campo y Dario Cecchi, Florencia: Usher-Arte, 2011: 101-108.

Desideri, Fabrizio. "Aura ex machina", Rivista di Estetica 52 (2013): 33-52

Fuld, Werner. "Walter Benjamins Beziehung zu Ludwig Klages", Akzente 28/3 (1983): 274-287.

Fürnkäs, Josef. "Aura”. Benjamins Begriffe, ed. Michael Opitz y Erdmut Wizisla, 2 ts., Fráncfort del Meno: Suhrkamp, 2000: 95-146.

Hugo, Victor. "À l'Arc de Triomphe", Les Voix intérieurs [1837]. OEuvres complètes (OEC), 45 ts., París: Paul Ollendorf-Albin Michel, 1904-1952.

Ibarlucía, Ricardo. Belleza sin aura. Surrealismo y teoría del arte en Walter Benjamin, Buenos Aires et al.: Miño y Dávila, 2020.

Kant, Immanuel. Kritik der praktischen Vernunft (KpV). Gesammelte Werke (Akademie Ausgabe), Parte I, t. 5. Berlín: G. Reimer, 1910 ss.

Klages, Ludwig. Der Geist als Widersacher der Seele, Bonn, Bouvier Verlag Herbert Grundmann, 6 ${ }^{\mathrm{a}}$ ed. 1981.

Lebovic, Nitznan. The Philosophy of Life and Death: Ludwig Klages and the Rise of a Nazi Biopolitcs, Nueva York: Palgrave McMillan, 2013.

Lindner, Burkhardt. "Benjamin Aurakonzeption: Anthropologie und Technik, Bild und Text". Walter Benjamin, 1892-1940, zum 100 Geburtstag, ed. Uwe Steiner, Berna: Peter Lang, 1992: 217-248.

McCole, John. Walter Benjamin and the Antinomies of Tradition, Ithaca NY: Cornell University Press, 1993.

Moretti, Giampiero Moretti. "Nimbus. Nota sulla questione dell' 'aura' in Ludwig Klages", Rivista di estetica 52 (2013): 149-159.

Novalis, Werke. Tagebücher und Briefe Friedrich von Hardenbergs (WTB) ed. Hans-Joachim Mähl y Richard Samuel, 3 ts., Múnich: Carl Hanser, 1978.

Nietzsche, Friedrich. Sämtliche Werke. Krtische Studienausgabe (KSA), ed. Giorgio Colli y Mazzino Montinari, 15 ts., Fráncfort del Meno: Waler de Gruyter, 1966-1978.

Salles, Georges. Le Regard - La collection. Le musée. La fouille. Une journée, L'école, París: Réunion des musées nationaux, 1992.

Steiner, Rudolf. Theosophie. Einführung in übersinnliche Welterkenntnis und Menschenbestimmung, Stuttgart, Der Kommende Tag A.-G., 1922.

Stendhal (Henri Beyle). De l’amour, ed. Henri Martineau, 2 ts., París: Le Di- 
van, 1927.

Tackels, Bruno. L'OEuvre d'art à l'époque de W. Benjamin: Histoire de l'aura, París, L'Harmattan, 1999.

Wohlfarth, Irving. "Walter Benjamin and the Idea of Technological Eros:

A Tentative Reading of Zum Planetarium", Benjamin Studien 1 (2002): 65-109. 